\title{
Differential Experience of Peer Victimisation Among Children With Learning Disabilities in Hong Kong
}

\author{
Jacob Yuichung Chan, ${ }^{1}$ Courtney M. Ryan, ${ }^{2}$ Annis L.C. Fung, ${ }^{3}$ Lawrence H. Gerstein, ${ }^{1}$ and \\ Rebecca M. Kinsey ${ }^{4}$ \\ ${ }^{1}$ Department of Counseling Psychology, Social Psychology, and Counseling, Ball State University, Muncie, Indiana, USA \\ 2 Psychologist, Greensburg, Pennsylvania, USA \\ ${ }^{3}$ Department of Applied Social Sciences, City University of Hong Kong, Hong Kong, China \\ ${ }^{4}$ Department of Psychology, Indiana University South Bend, South Bend, Indiana, USA
}

\begin{abstract}
$\mathrm{C}$ hildren with learning disabilities (LDs) are often targets of peer bullying. Studies have confirmed the distress associated with victimisation impairs academic performance. Research has also shown that boys experience victimisation differently than girls. This study examined whether students with LDs were more likely to be victimised, whether there was a gender difference in victimisation, and how students were victimised. Hong Kong children participated (162 with and 162 without LDs). Results indicated that students with LDs experienced increased levels of victimisation, and boys compared to girls with LDs sustained more physical victimisation. Academic performance did not significantly mediate the relationship between LDs and victimisation. Prevention and intervention strategies are discussed for this population.
\end{abstract}

Keywords: learning disabilities, victimisation, academic performance

Based on 'one curriculum framework for all', Hong Kong children with mild-to-moderate learning disabilities are placed in mainstream schools (Education Bureau, 2018). Along with this policy, a multitiered system is used to screen and assess children for learning disabilities by the Maternal and Child Health Centers of the Department of Health. All public primary schools assess each child in Primary One (1st grade equivalent) with the intention of identifying and intervening those with learning disabilities, among other difficulties. This procedure includes teacher evaluation of academic performance, social adjustment, and self-care skills. When learning difficulties are suspected, parents are informed and further assessment is recommended. After diagnosis by a specialist, interventions are devised to allow for continued education in mainstream classrooms while providing additional support.

The Hong Kong approach to inclusivity and mainstreaming is in agreement with a human rights perspective whereby no child should be segregated from others in any form. Professionals in special education support this view (Cook, Semmel, \& Gerber, 1999; Mittler, 1990). That being said, without adequate understanding of students with diversified needs, mainstream peers may discriminate against students with learning disabilities (Knight, 1999; Pivik, McComas \& LaFlamme, 2002).

Turning to peer discrimination, researchers have confirmed what parents and teachers already know: Children with learning disabilities are often the targets of bullying and aggression by their peers (Martlew \& Hodson, 1991; Nabuzoka \& Smith, 1993; Thompson, Whitney, \& Smith, 1994; Whitney, Nabuzoka, \& Smith, 1992). For example, interviews with elementary and middle school students (Albinger, 1995; Reid \& Button, 1995) confirmed the social degradation experienced by children with learning disabilities. Specifically, the researchers reported themes of anger, frustration and embarrassment in students over being removed from general education classrooms. Students also regularly reported becoming targets of verbal and physical attacks when their academic program involved time spent in special education and resource rooms.

The psychological self-concept of children with learning disabilities is linked with their peers. Beginning in elementary school, peers are key social agents in children's developing sense of self, with those who succeed academically and socially feeling largely confident, and those who

Address for correspondence: Jacob Yuichung Chan PhD, Teachers College 605, Department of Counseling Psychology, Social Psychology, and Counseling, Ball State University, IN 47306, USA. Email: ychan@bsu.edu 
fail often feeling inferior. This sense of inferiority can be enhanced greatly by acts of aggression and victimisation on the part of peers (Thijs \& Verkuyten, 2008). How children with learning disabilities experience peer victimisation and what factors mediate that experience, however, are less understood. This is the purpose of the current study.

Peer victimisation is often split into direct and indirect aggression. Direct aggression includes physical and verbal confrontational attacks, while indirect aggression includes manipulative attacks that are often covert in nature. Indirect aggression has also been labelled as relational or social aggression (Mynard \& Joseph, 2000). Mynard and Joseph (2000) introduced more categories to better elucidate the construct of peer victimisation and developed a multidimensional self-report scale based on responses of 812 English children aged from 11 to 16 years. Their analyses resulted in four subscales, including physical victimisation, verbal victimisation, social manipulation, and attacks on property.

\section{Learning Disabilities and Academic Performance}

When compared to their peers without learning disabilities, students with learning disabilities are typically below grade level (Cawley \& Miller, 1989), have a deficit in reading skills (Lyon, 1996), and poorer grades (Lerner, 1989). Peleg (2009) also discovered that students with learning disabilities experienced higher levels of test anxiety and lower levels of self-esteem than their peers without learning disabilities. The distress linked with test anxiety and low self-esteem also can impair their academic performance. The frustration associated with a constant struggle for academic success can result in students with learning disabilities developing maladaptive behaviours, including learned helplessness, lowered academic performance expectations, and negative affect, which can contribute to further academic difficulties.

\section{Academic Performance and Victimisation}

Researchers have found a relationship between low academic performance and increased peer victimisation. Thijs and Verkuyten (2008) studied 1,895 ethnically diverse 6th graders in 108 classrooms. While no significant results were found for ethnicity and peer victimisation, a negative relationship between academic achievement and victimisation was found. Similarly, Schwartz, Farver, Chang, and Lee-Shin (2002) also discovered that children with academic underachievement are often victimised. To clarify the dynamics involved, we tested the role of academic performance as a mediator between having a learning disability and experiencing higher rates of victimisation.

\section{Culture and Peer Victimisation}

Over the last two decades, researchers in China and Hong Kong have increasingly researched peer victimi- sation (Wong, 2004). Although severe school violence (e.g., mass shootings) is infrequent, direct bullying, such as insulting, taunting or hitting, is common, with estimates ranging from $13 \%$ (Wong, Lok, Lo, \& Ma, 2008) to $66 \%$ (Qiao, Xing, Ji, \& Zhang, 2009) depending on the area, socio-demographic characteristics, time frame the researchers asked participants to reflect upon, and type of peer victimisation (e.g., insults, exclusion, physical). Generally, males are more likely than females to be victimised by their peers in China and Hong Kong (Huang, Hong, \& Espelage, 2013). Peer victimisation rates tend to be highest in elementary school and decrease as students progress into middle and high school (Chen, 2001), but peer victimisation is more common among schools with lower academic banding (Wong, 2004). In a study conducted by Wong et al. (2008), $62 \%$ of the participants in 5 th and 6 th grade, were verbally bullied, $32 \%$ physically attacked, $28 \%$ socially excluded, and $13 \%$ experienced extortion. These are similar estimates to Wong's (2004) finding, with $31.7 \%$ of primary school students being physically attacked. Wong also provided further evidence that peer victimisation decreases as children age, with percentages of physical bullying victimisation dropping to $18.3 \%$ in a sample of secondary school students. Interestingly, these estimates appear to be higher than physical bullying estimates in the United States (10.6\%; Nansel et al., 2001). Tam and Taki (2007) proposed that bullying may occur in Hong Kong due to competition in large classrooms. Although they did not state this specifically, it is possible that individuals with learning disabilities are at an increased risk for being victimised by peers due to poor academic performance. Individuals in the classroom may be able to present themselves as doing better academically compared to others when they highlight the poorer academic success of individuals with learning disabilities, and they are motivated to do so because of the competition within the classroom. The relation between peer victimisation and learning disabilities will be further explored in subsequent sections.

\section{Gender and Peer Victimisation}

In the validation study of the Multidimensional Peer Victimization Scale, Mynard and Joseph (2000) examined the experience of victimisation among their respondents. In this sample, boys scored higher than girls on physical victimisation and attacks on property, while girls reported greater experiences of social manipulation. Boys and girls, however, did not vary in verbal victimisation. Previous studies have confirmed that male and female students are susceptible to different types of victimisation such that males reported higher levels of physical victimisation and females reported higher levels of relational and verbal victimisation (James \& Owens, 2004; Owens, Daly, \& Slee, 2005; Scheithauer, Hayer, Petermann, \& Jugert, 2006).

Interestingly, Hoglund (2007) purported that the perceived cost of experiencing different subtypes of 
victimisation served as a better indicator of gender differences. The researcher stated that girls may be disproportionately distressed by relational forms of victimisation as the loss of relationships is assigned greater value to them than for boys. Similarly, the loss of appearing dominant or strong holds a greater meaning for boys than for girls. Such perceptions may affect the proportions of subtypes reported. Turning to boys and girls with learning disabilities, Vogel (1990) reviewed the research and concluded that females with learning disabilities as compared to boys had lower IQ scores and poorer academic achievement in mathematics and reading. This suggests a gender difference in the learning disability experience that may affect the incidence and type of victimisation for this population.

\section{Learning Disabilities and Victimisation}

Mishna (2003) pointed out the significance of the cooccurrence of bullying and learning disabilities, which she called a 'double jeopardy' (p. 336), meaning that students with learning disabilities often have an impaired ability to read social cues and respond prosocially. This leaves them prone to victimisation and social isolation by mainstream peers that can lead to further emotional and psychological problems. Research purports that a snowball effect quickly forms, where the emotional and psychological problems quickly lead to worsening academic performance from a combination of demoralisation, more frequent disruptive behaviours, and increased distractibility, which again makes students with learning disabilities more visible targets for victimisation (Epstein, Cullinan, \& Lloyd, 1986; Kavale \& Forness, 1996; Mishna, 2003; Pearl \& Bay, 1999). Thus, academic performance may work as a mechanism to heighten the experience of victimisation for children with learning disabilities.

Along with few studies on the causes of peer victimisation for students with learning disabilities, there is limited research on how such persons are victimised (i.e., physically, verbally, relationally). For example, while Sabornie (1994) examined physical attacks and attacks on property of peers of students with learning disabilities, other possible ways of bullying (e.g., social rejection or verbal attacks) were not studied. More recently, however, victimisation has been evaluated, with reports substantiating elevated levels of direct and indirect aggression among teens with learning disabilities (McNamara, Willoughby, \& Chalmers, 2005). Further, Rose, Espelage, and MondaAmaya (2009) found increased rates of physical, verbal, and social peer victimisation for students enrolled in special education programs, as well as higher rates of bullying perpetration and fighting indicative of a cycle of deleterious behaviours.

While studies have examined the relationship of learning disabilities and academic performance, and academic performance and victimisation, to our knowledge no one has studied this performance as a mediator for victimisation of students with learning disabilities. Given this gap, this study explored whether students with learning disabilities were more likely to be victimised and, if so, how. That is, if they were victimised, was it the result of social manipulation, verbal or physical victimisation, attacks on property, or some combination of these behaviours? The current study also examined whether victimisation differed by gender. Finally, we investigated whether academic performance mediated the relationship between students' status of having learning disabilities or not and the victimisation they experienced.

We hypothesised that students with learning disabilities would be more likely to be victimised compared to students without learning disabilities. Further, we wanted to assess whether children with learning disabilities were more susceptible to one or more of the particular subtypes of victimisation. We also predicted that males with learning disabilities would experience more victimisation than females with learning disabilities. Finally, we hypothesised that academic performance would act as a mediating factor, whereby academic performance might partially explain the relationship between learning disabilities and peer victimisation.

\section{Method}

\section{Participants}

Participants were 324 students aged from 8 to 15 years $(M=9.85, S D=1.18)$ from seven elementary schools in Hong Kong. Despite the age range, based on one of the authors' experiences, it was assumed students encountered similar difficulties at school (e.g., stress related to academic performance, parental expectations, peer pressure). Students with (162) and without (162) learning disabilities were matched. Students with learning disabilities were an average age of 10.5 years (123 males and 39 females); students without learning disabilities were an average age of 10.3 years ( 118 males and 44 females). These two groups were matched for school, grade, and class, further controlling for potential contextual differences. That is, by matching for school, grade, and class, the academic environment, including educational resources and social factors, was highly similar for each pair of children.

\section{Procedures}

Upon approval from the University Ethical Board, Hong Kong elementary schools were invited to participate in the study as part of a leadership training program during the 2009-10 academic year. Students in Grades 4 through 6 were invited to participate. Parental consent was obtained by sending parents a letter and asking them to reply. Following consent, students completed electronic surveys during class. Parent surveys were also given to students' parents to gain insight from the parents' perspectives.

A total of 3,665 students participated in this program. Of this sample, 1,985 pairs of parents and students (54\% of the total sample) completed both the parent and student surveys. Parents were asked about their children's 
history of learning disabilities by indicating whether their child was diagnosed with any learning disabilities, and if so, what kind. Of the 1,985 pairs, parents of 162 students clearly indicated their child had a learning disability. It is important to note that while identifying students with a learning disability was based on parent report, Chinese cultural norms would inhibit parents from falsely reporting a learning disability in their child. Additionally, the parents had no known reason to falsely report that their child had a learning disability, as they were not offered additional services or any monetary compensation if they had made such a claim. Because there were unequal cell sizes for students with and without learning disabilities, we further matched students with learning disabilities with their peers using their school, grade, and class. We carried out the matching process by randomly choosing students without learning disabilities in the same school, grade, and class as those with learning disabilities. By matching and controlling for these key variables, we were able to more confidently evaluate whether learning disabilities had a role in victimisation.

\section{Measures}

Multidimensional Peer Victimisation Scale (MPVS). The MPVS (Mynard \& Joseph, 2000) is a 16-item, self-report scale that assesses four different forms of victimisation: physical (e.g., 'Punched me'), verbal (e.g., 'Called me names'), social manipulation (e.g., 'Tried to get me into trouble with my friends'), and attacks on property (e.g., 'Took something of mine without permission'). Each form consists of four items. Frequency of victimisation is reported using a 5-point Likert scale with 0 as never, 1 as once, 2 as twice, 3 as thrice, 4 as four times or above. Mynard and Joseph (2000) reported internal consistency estimates using Cronbach's alpha as .85 for physical victimisation, .75 for verbal victimisation, .77 for social manipulation, and .73 for attacks on property. The coefficient alpha reliability estimate found for the current sample total score was .90 , while the subscales had reliabilities of .85 (physical victimisation), .79 (verbal victimisation), .83 (social manipulation), and .77 (attacks on property). Students in our sample were given the MPVS.

Academic performance. We obtained students' academic performance, defined as the mean score of the final term examination in the past academic year, from their respective schools. Because schools could vary in their student composition and backgrounds, we classified students into 'poor academic results' and 'satisfactory academic results' using the 25th percentile of individual schools' academic scores as cutoff points. Given that final examination scores were not generated from public but rather internal examinations, we thought this to be a more accurate reflection of students' relative status in academic performance. For example, a student with an average final examination score of 60 out of 100 could be regarded as having poor academic performance in a high-ranked school, but a good academic performance in a low-ranked school. In our sample, of the 162 students with learning disabilities, 114 had poor academic results while 52 matched students without learning disabilities had poor academic results.

\section{Results}

Variables were examined for the assumptions of multivariate statistics. The MPVS total and subscale scores were found to violate some of the assumptions and were transformed using the square root method. To test the hypotheses, three sets of analyses were performed. For the first hypothesis, a multivariate analysis of covariance (MANCOVA) with learning disabilities (learning disability vs. non-learning disability) as the between-subject factor, gender (male vs. female) as a covariate, and the four types of victimisation as the dependent variables was computed. A multivariate analysis of variance (MANOVA) was used to test the second hypothesis: gender difference in different subtypes of victimisation among students with learning disabilities. Baron and Kenny's (1986) article on distinguishing mediators and moderators guided the test of the third hypothesis. The mediation analysis involved learning disability/non-learning disability as the independent variable (IV), academic performance as the mediator, and peer victimisation as the dependent variable (DV). Since this mediation analysis involved the use of a dichotomous mediator (academic performance: poor vs. satisfactory), we followed guidelines provided by MacKinnon and Dwyer (1993) on testing a mediation model with a dichotomous mediator and/or DV.

Among different types of peer victimisation, verbal victimisation $(M=4.21, S D=4.40)$ was the most prevalent, followed by social manipulation $(M=3.07, S D=$ 3.99), physical victimisation $(M=2.86, S D=4.19)$, and attacks on property $(M=2.47, S D=3.46)$. Prior to the main analysis, the assumptions of multivariate analysis were investigated. To reduce skewness and kurtosis of the four subtypes of victimisation, a squared-root transformation was applied.

\section{Effect of Learning Disabilities on Types of Victimisation}

To examine the first hypothesis that students with as compared to without learning disabilities would be more likely to be victimised, a one-way MANCOVA was performed on the four DVs (physical victimisation, verbal victimisation, social manipulation, and attacks on property). Gender was a covariate and the IV was learning disabilities (learning disability and non-learning disability). The overall effect of learning disabilities was found to be significant, Wilks's $\Lambda=.96, F(4,318)=2.97, p<.05$, partial $\eta^{2}=.04$; that is, there were more victimisations in the learning disability group. An overall significant effect for gender was found as well, Wilks's $\Lambda=.95, F(4,318)=4.65, p<.001$, partial $\eta^{2}=.06$. Univariate tests for learning disabilities showed that students with learning disabilities reported significantly more verbal victimisation than students without 
Table 1

Comparison of Group Scores on Multidimensional Peer-Victimisation Scale $(N=324)$

\begin{tabular}{|c|c|c|c|c|}
\hline \multirow[b]{2}{*}{ MPVS } & \multicolumn{2}{|c|}{$\begin{array}{l}\text { Students without } \\
\text { disabilities }\end{array}$} & \multicolumn{2}{|c|}{$\begin{array}{l}\text { Students with } \\
\text { disabilities }\end{array}$} \\
\hline & $M$ & $S D$ & $M$ & $S D$ \\
\hline Total & 11.34 & 12.73 & 13.87 & 12.89 \\
\hline PV & 2.64 & 4.26 & 3.08 & 4.12 \\
\hline $\mathrm{VV}^{*}$ & 3.40 & 3.91 & 5.03 & 4.71 \\
\hline SM & 2.87 & 3.85 & 3.26 & 4.13 \\
\hline$A P$ & 2.43 & 3.52 & 2.50 & 3.42 \\
\hline \multicolumn{5}{|c|}{$\begin{array}{l}\text { Note: } \mathrm{PV}=\text { physical victimisation, } \mathrm{VV}=\text { verbal victimisation, } \mathrm{SM}=\text { social manipulation, } \\
\mathrm{AP}=\text { attacks on property } \\
* p<.01\end{array}$} \\
\hline
\end{tabular}

\section{Table 2}

Comparison of Gender Differences Within Students With Learning Disabilities on Multidimensional Peer-Victimisation Scale $(N=162)$

\begin{tabular}{lccccc}
\hline & \multicolumn{2}{c}{ Boys $(\mathrm{N}=123)$} & & \multicolumn{2}{c}{ Girls $(\mathrm{N}=39)$} \\
\cline { 2 - 3 } \cline { 6 - 6 } MPVS & $M$ & $S D$ & & $M$ & \multicolumn{1}{c}{$S D$} \\
\hline Total & 14.43 & 13.52 & & 12.12 & 10.62 \\
PV* & 3.56 & 4.40 & & 1.57 & 2.86 \\
VV & 4.93 & 4.73 & & 5.33 & 4.69 \\
SM & 3.29 & 4.22 & & 3.15 & 3.89 \\
AP & 2.63 & 3.60 & & 2.07 & 2.78 \\
\hline
\end{tabular}

Note: $\mathrm{PV}=$ physical victimisation, $\mathrm{VV}=$ verbal victimisation, $\mathrm{SM}=$ social manipulation, $\mathrm{AP}=$ attacks on property

$* p<.05$.

learning disabilities, $F(1,321)=9.12, p<.01$, partial $\eta^{2}=.028$. The mean scores and standard deviations for different types of victimisation behaviours between students with and without learning disabilities are reported in Table 1 .

To test the second hypothesis that males with learning disabilities would be more likely to be victimised by peers than females with learning disabilities, a one-way MANOVA was employed. The overall effect of gender was significant, Wilks's $\Lambda=.93, F(4,157)=3.20, p<.05$, partial $\eta^{2}=.08$; that is, boys with learning disabilities experienced more victimisation compared to girls. Univariate tests for gender indicated that boys with learning disabilities reported significantly more physical victimisation than girls with learning disabilities, $F(1,160)=7.57$, $p=.01$, partial $\eta^{2}=.045$. The mean scores and standard deviations for different types of victimisation behaviours between boys and girls with learning disabilities are reported in Table 2.

A mediation analysis was performed to test the third hypothesis that academic performance would mediate the relationship between learning disabilities and peer victimisation. Because we found that the only significant difference between students with and without learning disabilities was linked with verbal victimisation, we used this variable in the analysis. However, after following the steps recommended by Sobel (1982) and Preacher and Hayes (2008), the results of the Sobel $z$ test failed to support the mediation model $(z=-.383, p>.05)$. In addition, the relationship between academic performance and verbal victimisation in our sample was not significant. Academic performance in our sample did not significantly predict verbal victimisation $(p=.701)$. This does not satisfy the mediation criteria by Baron and Kenny (1986).

\section{Discussion}

We proposed that students with learning disabilities would be more likely to be victimised compared to students without learning disabilities. Our results partially supported this prediction, such that children with learning disabilities experienced more verbal victimisation compared to children without learning disabilities. Children with and without learning disabilities reported similar experiences of physical victimisation, social manipulation, and attacks on property. A plausible explanation for the increased rate of verbal victimisation toward Hong Kong students with learning disabilities could be described as a labelling effect whereby explicitly being classified as having learning disabilities also bears implicit meanings of being less capable, having lower social status, and poorer social relationships (Mishna, 2003). This explanation is consistent with Reid and Button (1995), who found that children with learning disabilities felt unappreciated and misunderstood by peers and teachers. It is also congruent with a call for education systems to recognise the deficit in proper training for teachers of this population (Mittler, 2002). Further study is needed to enhance our understanding of the dynamics connected to students with learning disabilities' heightened susceptibility to peer victimisation.

We were also interested in the relationship between gender and victimisation. Results partially supported our prediction that boys compared to girls would report more victimisation as male participants experienced more physical aggression than girls. While our overall hypothesis was not confirmed, the victimisation of the physical type for males was in accordance with the literature and our hypothesis. This is consistent with previous research (Mynard \& Joseph, 2000), as well as Card, Stucky, Sawalani, and Little's (2008) meta-analysis, in which they found direct aggression at higher rates in males, but indirect aggression was not significant by gender.

Our significant results have important theoretical implications. Given that we found significant gender effects, it would be important to continue to assess the effect of gender on victimisation in future victimisation research in Hong Kong and not assume that victimisation is the same for each gender. Additionally, our results were similar to findings obtained in the United States (Baumeister, Storch, \& Geffken, 2008; Carter \& Spencer, 2006). This provides evidence that the increased likelihood of being victimised if a student has a learning disability may be a cross-cultural phenomenon. As such, students in Hong Kong may benefit from comparable intervention programs implemented in the United States. However, as other researchers have recommended (Rose, Monda-Maya, \& Espelage, 2011), 
specific interventions need to be created to prevent individuals with learning disabilities from being victimised, given that they are at an increased risk of victimisation. Simple prevention programs are not enough; prevention programs tailored to protect individuals with learning disabilities are warranted (Rose et al., 2011).

Our results did not support the mediation model we hypothesised. Academic achievement did not mediate the link between learning disability status and susceptibility to victimisation. Recall that academic performance in our sample failed to predict verbal victimisation $(p=.701)$. This result seemed to indicate that academic performance in this group of students may not be the contributing factors to verbal victimisation, regardless of their learning disability status. Academic performance thus may not be a factor in explaining the mechanism between learning disabilities and verbal victimisation from peers in our sample. Additionally, the model may have failed because the changes adopted by the Hong Kong schools in recognition of learning disabilities may have played a stronger role in demarcating children than poor grades. That is, children with learning disabilities may have received a modified education plan that included separate special education classes or one-on-one classroom assistance. These modifications may be more immediately apparent to other classmates than poor academic performance. Such modifications might even be viewed as differential treatment that would likely serve as a more powerful instigator of discrimination and maltreatment than a more easily hidden report card.

Given the role of other psychological constructs related to having a learning disability (e.g., low self-esteem, anxiety, and difficulty with cognitive self-regulation), professionals are unsure how student victimisation is provoked and what can be done to prevent it. The prevention of student victimisation becomes particularly complex when special education needs must be considered alongside delivery and setting of special education services. Salend and Garrick Duhaney (1999) reported on a 1995 national study by the National Center for Educational Restructuring and Inclusion, which provided evidence that receiving individualised assistance while remaining in the general education classroom aided students with learning disabilities in improving academic motivation and performance, obtaining higher standardised test scores and bettering classroom behaviour. Of particular relevance to our findings, students in these inclusion programs also demonstrated improved interactions with peers and better attitudes toward school when compared to students who spent more time in special education classrooms. As our findings suggest, academic performance alone does not seem to play a role in students' vulnerability to victimisation. Rather, differences perceived by peers in how education is delivered likely play a greater role.

Students with learning disabilities are at risk of increased victimisation by their peers. Stated bluntly, their peers have identified them as targets for bullying (Martlew
\& Hodson, 1991; Nabuzoka \& Smith, 1993; Thompson et al., 1994; Whitney et al., 1992). Consequently, mental health professionals, researchers, and educators must develop and implement programs and policies designed to ensure their safety and allow for a healthier environment more conducive to learning. As Bender and Wall (1994) pointed out, to reach the full benefits of inclusive classrooms, children with learning disabilities must be supported in obtaining meaningful participation in social and academic activities.

While a compelling explanation for victimisation of students with learning disabilities remains unknown, extant research, including this study, provides support for prevention and intervention programs. Our results can be understood as implicating the need for acceptance and understanding of students with learning disabilities. Well implemented inclusion programs may expose students without learning disabilities to those with learning disabilities, allowing for differences to be diminished and misunderstandings linked with leaving for pull-out classes to be reduced. Saylor and Leach (2009) insisted, however, that simply having students with learning disabilities in the same classroom is insufficient. Rather, teachers, aides, and psychologists, along with parents and families, must work to facilitate full social inclusion (Mittler, 1990). In other words, students with learning disabilities can often be excluded to a separate table at lunch or a corner of the classroom where social opportunities are still limited to engaging aides or other students with learning disabilities. A successful inclusion program must offer integrated social opportunities that improve social skills and confidence while negating the risk of victimisation (Estell et al., 2009). Cook et al. (1999) argued that principals are in a key position to implement effective inclusion policies as they have control over educational resources and stand in a supervisory position allowing for direct influence over the implementation of such programs.

Our study further confirmed that verbal forms of victimisation occur at higher rates for Hong Kong students with learning disabilities, and facing physical aggression is more common for males. The study also revealed that academic performance does not seem to mediate learning disability status and victimisation. Implications for inclusion policies can be derived from our results. Wellintentioned inclusion programs may not provide students with learning disabilities an equivalent educational experience. Programs are needed to ensure full social inclusion that transcends simply sharing the same learning space.

\section{References}

Albinger, P. (1995). Stories from the resource room: Piano lessons, imaginary illness, and broken-down cars. Journal of Learning Disabilities, 28, 615-621.

Baron, R., \& Kenny, D. (1986). The moderator-mediator variable distinction in social psychological research: Conceptual, strategic, and statistical considerations. Journal of Personality and Social Psychology, 51, 1173-1182. 
Baumeister, A.L., Storch, E.A., \& Geffken, G.R. (2008). Peer victimization in children with learning disabilities. Child and Adolescent Social Work Journal, 25, 11-23. doi:10.1007/s10560-007-0109-6

Bender, W., \& Wall, M. (1994). Social-emotional development of students with learning disabilities. Learning Disabilities Quarterly, 17, 323-341.

Card, N.A., Stucky, B.D., Sawalani, G.M., \& Little, T.D. (2008). Direct and indirect aggression during childhood and adolescence: A meta-analytic review of gender differences, intercorrelations, and relations to maladjustment. Child Development, 79, 1185-1229.

Carter, B.B., \& Spencer, V.G. (2006). The fear factor: Bullying and students with disabilities. International Journal of Special Education, 21, 11-23.

Cawley, J., \& Miller, J. (1989). Cross-sectional comparisons of the mathematical performance of children with learning disabilities: Are we on the right track toward comprehensive programming? Journal of Learning Disabilities, 22, 250254.

Chen, S. (2001). The investigation of school bullying in elementary, middle, and high schools. Social Psychology Research, 1, 24-28.

Cook, B., Semmel, M., \& Gerber, M. (1999). Attitudes of principals and special education teachers toward the inclusion of students with mild disabilities critical differences of opinion. Remedial and Special Education, 20, 199-298.

Education Bureau. (2016). Special educational needs. Retrieved September 10, 2016, from http://www.edb.gov.hk/ en/curriculum-development/major-level-of-edu/specialeducational-needs/index.html

Education Bureau. (2018, November 18). Special Education. Retrieved from https://www.edb.gov.hk/en/edu-system/ special/policy-and-initiatives/special-edu/index.html

Epstein, M., Cullinan, D., \& Lloyd, J. (1986). Behavior-problem patterns among the learning disabled: III. Replication across age and sex. Learning Disability Quarterly, 9, 43-54.

Estell, D., Farmer, T., Irvin, M., Crowther, A., Akos, P., \& Boudah, D. (2009). Students with exceptionalities and the peer group context of bullying and victimization in late elementary school. Journal of Child and Family Studies, 18, 136150.

Hoglund, L. (2007). School functioning in early adolescence: Gender-linked responses to peer victimization. Journal of Educational Psychology, 99, 683-699.

Huang, H., Hong, J.S., \& Espelage, D.L. (2013). Understanding factors associated with bullying and peer victimization in Chinese schools within ecological contexts. Journal of Child and Family Studies, 22, 881-892.

James, V., \& Owens, L.D. (2004). Peer victimisation and conflict resolution among adolescent girls in a single-sex south australian school. International Education Journal, 5, 3749.

Kavale, K., \& Forness, S. (1996). Social skill deficits and learning disabilities: A meta-analysis. Journal of Learning Disabilities, 29, 226.
Knight, B. (1999). Towards inclusion of students with special educational needs in the regular classroom. Support for Learning, 14, 3-7.

Lerner, J. (2003). Learning disabilities: Theories, diagnosis, and teaching strategies. New York, NY: Houghton Mifflin.

Lerner, J.W. (1989). Learning disabilities: Theories, diagnosis, and teaching strategies, Houghton Mifflin Harcourt (HMH).

Lyon, G. (1996) Learning disabilities. The Future of Children, 6, $54-76$.

MacKinnon, D., \& Dwyer, J. (1993). Estimating mediated effects in prevention studies. Evaluation Review, 17, 144158.

Martlew, M., \& Hodson, J. (1991). Children with mild learning difficulties in an integrated and in a special school: Comparisons of behaviour, teasing and teachers' attitudes. British Journal of Educational Psychology, 61, 355-372.

McNamara, J., Willoughby, T., \& Chalmers, H. (2005). Psychosocial status of adolescents with learning disabilities with and without comorbid attention deficit hyperactivity disorder. Learning Disabilities Research and Practice, 20, 234244.

Mishna, F. (2003). Learning disabilities and bullying: Double jeopardy. Journal of Learning Disabilities, 36, 336-347.

Mittler, P. (1990). Prospects for disabled children and their families: An international perspective. Disability, Handicap and Society, 5, 53-64.

Mittler, P. (2002). Educating pupils with intellectual disabilities in England: Thirty years on. International Journal of Disability, Development and Education, 49, 145-160.

Mynard, H., \& Joseph, S. (2000). Development of the Multidimensional Peer-Victimization Scale. Aggressive Behavior, 26, 169-178.

Nabuzoka, D., \& Smith, P. (1993). Sociometric status and social behaviour of children with and without learning difficulties. Journal of Child Psychology and Psychiatry, 34, 14351448.

Nansel, T.R., Overpeck, M., Pilla, R.S., Ruan, W.J., SimonMorton, B., \& Scheidt, P. (2001). Bullying behaviors among U.S. youth: Prevalence and association with psychosocial adjustment. Journal of the American Medical Association, 485, 2094-2100.

Owens, L., Daly, A., \& Slee, P. (2005). Sex and age differences in victimisation and conflict resolution among adolescents in a south Australian school. Aggressive Behavior, 31, 1-12.

Pearl, R., \& Bay, M. (1999). Psychosocial correlates of learning disabilities. In V.L. Schwean \& D.H. Saklofske (Eds.), Handbook of psychosocial characteristics of exceptional children (pp. 443-470). New York, NY: Kluwer Academic/Plenum Publishers.

Peleg, O. (2009). Test anxiety, academic achievement, and selfesteem among Arab adolescents with and without learning disabilities. Learning Disability Quarterly, 32, 11-20.

Pivik, J., McComas, J., \& LaFlamme, M. (2002). Barriers and facilitators to inclusive education. Exceptional Children, 69, 97-107. 
Preacher, K., \& Hayes, A. (2008). Asymptotic and resampling strategies for assessing and comparing indirect effects in multiple mediator models. Behavior Research Methods, 40, 879-891.

Qiao, Y.J., Xing, Y., Ji, C.Y., \& Zhang, L. (2009). The prevalence of bullying behaviors among urban middle school students in 18 provinces, China. Zhonghua Liu Xing Bing Xue Za Zhi, 30, 444-447.

Reid, D., \& Button, L. (1995). Anna's story: Narratives of personal experience about being labeled learning disabled. Journal of Learning Disabilities, 602-614.

Rose, C., Espelage, D., \& Monda-Amaya, L. (2009) Bullying and victimisation rates among students in general and special education: A comparative analysis. Educational Psychology, 29, 761-776.

Rose, C.A., Monda-Amaya, L.E., \& Espelage, D.L. (2011). Bullying perpetration and victimization in special education: A review of the literature. Remedial and Special Education, 32, 114-130. doi:10.1177/0741932510361247

Sabornie, E. (1994). Social-affective characteristics in early adolescents identified as learning disabled and nondisabled. Learning Disability Quarterly, 17, 268-279.

Salend, S., \& Garrick Duhaney, L.M. (1999). The impact of inclusion on students with and without disabilities and their educators. Remedial and Special Education, 20, 114.

Saylor, C., \& Leach, J. (2009). Perceived bullying and social support in students accessing special inclusion programming. Journal of Developmental and Physical Disabilities, 21, 6980.

Scheithauer, H., Hayer, T., Petermann, F., \& Jugert, G. (2006). Physical, verbal, and relational forms of bullying among
German students: Age trends, gender differences, and correlates. Aggressive Behavior, 32, 261-275.

Schwartz, D., Farver, J.M., Chang, L., \& Lee-Shin, Y. (2002). Victimization in South Korean children's peer groups. Journal of Abnormal Child Psychology, 30, 113-125.

Sobel, M. (1982). Asymptotic confidence intervals for indirect effects in structural equation models. Sociological Methodology, 12, 290-312.

Tam, F.W.M., \& Taki, M. (2007). Bullying among girls in Japan and Hong Kong: An examination of the frustrationaggression model. Educational Research and Evaluation, 13, 373-399.

Thijs, J., \& Verkuyten, M. (2008). Peer victimization and academic achievement in a multiethnic sample: The role of perceived academic self-efficacy. Journal of Educational Psychology, 100, 754-764.

Thompson, D., Whitney, I., \& Smith, P. (1994). Bullying of children with special needs in mainstream schools. Support for Learning, 9, 103-106.

Vogel, S. (1990). Gender differences in intelligence, language, visual-motor abilities, and academic achievement in students with learning disabilities: A review of the literature. Journal of Learning Disabilities, 23, 44-52.

Whitney, I., Nabuzoka, D., \& Smith, P. (1992) Bullying in schools: Mainstream and special needs. Support for Learning, 7, $3-7$.

Wong, D.S. (2004). School bullying and tackling strategies in Hong Kong. International Journal of Offender Therapy and Comparative Criminology, 48, 537-553.

Wong, D.S., Lok, D.P., Wing Lo, T., \& Ma, S.K. (2008). School bullying among Hong Kong Chinese primary schoolchildren. Youth \& Society, 40, 35-54. 